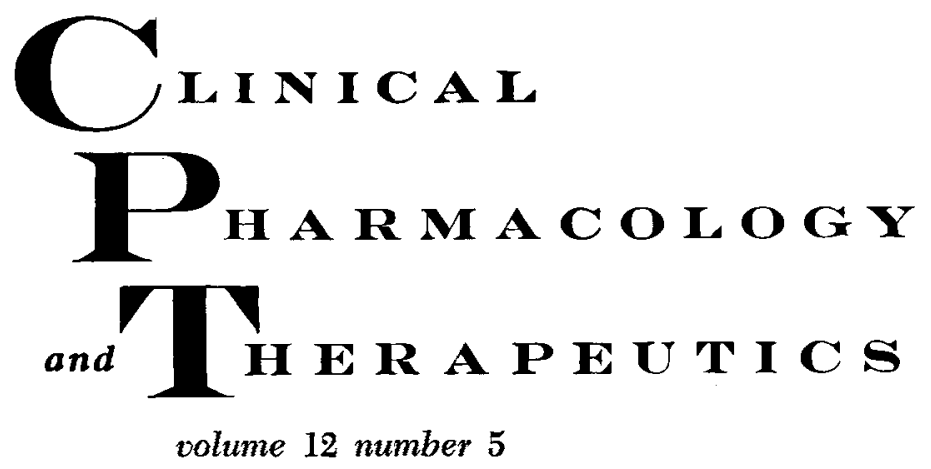

September-October, 1971

\title{
Commentary The Washington Conference on Clinical Pharmacology
}

\author{
Edward A. Carr, Jr., M.D. \\ Ann Arbor, Mich. \\ Departments of Pharmacology and Internal Medicine, and The Upjohn Center for \\ Clinical Pharmacology, University of Michigan
}

The Drug Research Board of the National Academy of Sciences-National Research Council convened a Conference on Clinical Pharmacology in Washington, D. C., on December 3 and 4, 1970.* For two days the participants reviewed the status and future possibilities of Clinical Pharmacology. In some instances the view-

This review of the Conference is not to be construed as an official report of the Drug Research Board. The opinions given herein do not necessarily reflect the official views of any sponsoring group. Participants included: Drs. C. L. Dunham, Leon I. Goldberg (Chairman), Alexander Leaf, Thomas H. Maren, B. L. Martz, John A. Oates, Henry W. Elliott, Daniel X. Freedman, Kenneth L. Melmon, Paul Palmisano, Marion J. Finkel, C. Gordon Zubrod, Byron Clark, I. C. Winter, Daniel L. Azarnoff, Edward Pelikan, Alan Bass, Emanuel M. Papper, Thomas L. Whitsett, Clifford Gurley, Arthur P. Richardson, Kenneth G. Kohlstaedt, Robert M. Hodges, John J. Burns, C. N. Christensen, Harold F. Hailman, Maurice Nance, David P. Rall, Theodore Cooper, Charles C. Edwards, Jr., Albert Sjoerdsma, Lyndon Lee, Thomas M. Durant, Alfred Gilman, Franz Gross, and Edward A. Carr, Jr. Mr. Duke Trexler was the Executive Secretary. For purposes of brevity, participants are identified only by last names in the text of this report.

- Other sponsoring groups were the American Society for Clinical Pharmacology and Therapeutics, the American Society for Pharmacology and Experimental Therapeutics, the Food and Drug Administration, the National Institute of General Medical Sciences, the Pharmaceutical Manufacturers Association, Inc., and the Veterans Administration. points of several individuals blended well in support of an idea, while a clear separation occurred on the other occasions "The Conference thus afforded an opportunity to gauge the state of opinion on many important issues related to clinical pharmacology.

As Elliott pointed out, recorded interest in therapy extends as far back as Sumerian tablets. Although the Conference concerned itself largely with the present and future, quotations from Aristotle, Spenser, Oliver Wendell Holmes, Thoreau, and the Chicago Tribune occurred at one time or another during the two days. The ability to bring Thoreau and the Chicago Tribune together in one program is perhaps emblematic of the breadth of interest of clinical pharmacologists.

For those who consider the sulfonamides to be the class of drug that initiated modern pharmacology, Zubrod's presentation was appropriate. He traced the grow-

\footnotetext{
In preparing this commentary I have been greatly aided by additional notes of the Conference taken by Drs. Daniel Azarnoff, Henry Elliott, and Kenneth Melmon. Their cooperation is gratefully acknowledged.
} 
ing interest of Perrin Long and E. K. Marshall, who were so intimately involved with chemotherapy of infection during the sulfonamide era, in the development of clinical pharmacology as an area of teaching, research, and patient care at Johns Hopkins University during the period 1946 to 1953. This interest culminated in the establishment of a regular clinical pharmacology program under Dr. Louis Lasagna in 1955. This was an important advance for clinical pharmacology, second only to the studies of cardiac glycosides in man by Drs. Harry Gold and Walter Modell, who were the clinical pharmacology pioneers of this century.

In the present 1970 Conference, Pelikan noted that the clinical pharmacologist is still easier to define than his field. Burns suggested that clinical pharmacology may best be defined as the study of drug actions in man. In the course of his plea to avoid isolating clinical pharmacology training from the training of basic pharmacologists and toxicologists, Pelikan stated that all these individuals are engaged in the systematic study of the interaction of drugs with living organisms; clinical pharmacologists study drugs that have somewhat more immediate reference to health, using systems that more closely imitate the intended use of the compounds in medicine. Lee, reviewing the activities of clinical pharmacologists in Veterans Administration Hospitals, stated that he still has difficulty in defining clinical pharmacology precisely. Questions of definition will apparently continue to trouble this interdisciplinary activity for many years.

Nevertheless, the participants agreed widely with Goldberg's statement, made early in the Conference, that disagreements about definition occupy less attention than formerly. Previous conferences had revealed great concern about the "image" of clinical pharmacology, and even its viability. Such anxiety was much less evident in the early phase of the present Conference. Pelikan's concern for the training of larger numbers of basic pharmacologists as well as clinical pharmacologists received support (Hodges), and the definition of pharmacology itself was a pertinent topic. Maren defined pharmacology as the study of the interaction of drugs with large molecules. In a previous meeting of training grant directors, held under the auspices of the National Institute of General Medical Sciences (NI GMS) in San Francisco in 1969, the definition of pharmacology itself had also been discussed. At that time Dr. Walter Riker had stressed selective toxicity as the most central concern of pharmacology, with doseresponse and time-action curves as two of its most characteristic ways of treating data.

The realization that the increase in new drugs calls for increasing atttention to clinical pharmacology led to many intramural and extramural clinical pharmacology activities at the National Institutes of Health (NIH). Clark reviewed those established by NIGMS and noted that important support has also been given by two other institutes, the National Heart and Lung Institute (NHLI) and the National Cancer Institute (NCI). In the intramural programs of the NIH the most effective obstetrician for clinical pharmacology has been Sjoerdsma. In the period 1958 to 1964 he explored an extensive series of new compounds in man and in the course of doing this delivered an astonishing number of trained individuals into the world. The graduates of his program are directors and staff members of other clinical pharmacology programs all over the country. Burns and Hodges added their strong support to his view that the investigation of new compounds in man is the most essential activity of the clinical pharmacologist.

Extramural direct support of clinical pharmacology from NIGMS began at Oklahoma, although NIGMS had already been supporting clinical pharmacology indirectly in programs at Cornell, Penn, California, Southwestern, and Michigan before that 
time. (The program at Oklahoma fostered many studies of new compounds in man under the excellent direction of the late Dr. John Colmore, whose recent death was noted with sadness by the conferees.) Support of clinical pharmacology by NHLI (at that time National Heart Institute) began early in the last decade at Emory, Johns Hopkins, and Michigan. Clark noted that annual training program support for clinical pharmacology is now approximately $\$ 306,000$ (6 programs) from NIGMS, $\$ 310,000$ (6 programs) from NHLI, and $\$ 124,000$ (3 programs) from NCI. Cancer chemotherapy, like anesthesiology, may be considered as one of the purest forms of clinical pharmacology, as Zubrod and Elliott, respectively, reminded the Conference. The Pharmacology-Toxicology Programs of NIGMS now provide about $\$ 18,000,000$, of which 3 to 4 million go to centers and large program projects. In addition to direct support of clinical pharmacology by NIGMS, there is important indirect support through programs which are not entirely clinical pharmacology but still have an important clinical pharmacology component. Approximately $\$ 5,000,000$ of the total support of clinical research centers throughout the country may be considered support of activities in the clinical pharmacology area. Certain activities of NHLI and NCI may be considered indirect support of clinical pharmacology, somewhat analogous to that given by NIGMS. In answer to a question from the audience, it was stated that a considerable amount of medical school teaching, including postgraduate teaching, receives indirect support from the numerous NIH funds memtioned above, although the medical schools themselves may not always take the best advantage of the possibilities offered to them in this regard.

Winter described support of clinical pharmacology by the Pharmaceutical Manufacturers Association (PMA), as he reviewed the history of programs that began in 1965. Nineteen faculty develop- ment awards have been given, as well as a wide variety of other types of support, including fellowships for medical students, etc. In addition to support by PMA as a group, at least ten companies support clinical pharmacology through some form of individual effort. Earlier in the Conference Elliott had mentioned that one possible solution to the problern of finding sufficient space for clinical pharmacology in various medical centers was the housing of all clinical pharmacology activities in one building devoted entirely to this field and had used the Upjohn Center at Michigan as an example. Richardson discussed the need for clinical pharmacology groups to have their own financial support, space, recruiting program, and research program, although he did not favor the establishment of clinical pharmacology groups as separate departments. Such an interdisciplinary activity, not based in any single department, requires strong support from the dean's office in each medical school. In making this last point, Richardson was reiterating a major conclusion of the Basin Harbor Conference of 1965. Although little support for the idea of separate clinical pharmacology departments was expressed by anyone at the present Conference, the concept of clinical pharmacology as a specialty in itself provoked some debate. Cooper supported this concept, while Zubrod questioned it.

Thus far one may have the picture of a group moderately pleased with its own progress in overcoming severe problems that had been apparent as recently as five years ago and fairly hopeful that the modus vivendi between clinical pharmacology and basic pharmacology, so recently developed, would prove workable. But any complacency about this last suggestion was broken by a loud "nyet" from Leaf. In a calm, quiet presentation Leaf gave the most provocative talk of the Conference. He claimed that the increase in number of drugs, which has recently received so much attention, really means an increase in the need for subspecialists 
to teach about their specific classes of drug in the setting of a good clinical department. Leaf feels that good clinical departments are the places in which one finds the best research in the use of drugs. $\mathrm{He}$ believes that quality control can best be achieved by having clinical pharmacologists in subspecialty units. As to the fate of pharmacology departments themselves, they may continue to exist or, alternatively, a consortium of clinicians engaged in good drug research may replace the traditional activities of a pharmacology department, he suggested. Though no other speaker supported Leaf's proposal in toto, many comments of other speakers could be interpreted as consistent with Leaf's thesis. Oates stressed the importance of good clinical training for clinical pharmacologists, and Richardson called further attention to the large amount of good clinical pharmacology performed by people who do not call themselves clinical pharmacologists. Perhaps the lack of any formal affiliation with pharmacology is not very harmful after all, Richardson added. Hailman estimated that about 85 per cent of the clinical pharmacology required by industry is at present conducted by specialists who do not call themselves clinical pharmacologists, and Papper referred to many clinical pharmacologists as "internists in disguise." Gurley observed that it is easier to convert an M.D. into a pharmacologist than to convert a Ph.D. into a clinician and added that some basic scientists are now leaving their bases in medical schools to join undergraduate university departments. Maren admitted that close relation to pharmacology does indeed slow the recruiting of clinical pharmacologists. Even course work may not require a department for its organization; Gurley emphasized that many courses are now planned by committees rather than departments (a development that Bass deplored). At present many clinical pharmacologists do not have "the security of an organ system," in Oates' phrase, and are often ill at ease with basic pharmacologists, according to Freedman and Papper. Papper also described the worries of many clinical pharmacologists about possible loss of clinical skills if too much time is spent in basic pharmacology. All 36 clinical pharmacology programs described in Azarnoff's report to the Conference have relations with the departments of internal medicine, and one may therefore assume that such departments provide a reasonable environment for clinical pharmacology. Pharmacology itself is often considered irrelevant by students, Whitsett stated.

But comments in opposition to Leaf's ideas were even more frequent than those supporting him. Maren stated that his pharmacology department had developed a good clinical pharmacology program and clinicians have been happy to have this relation with pharmacology. The panel method of teaching provides an opportunity to bring clinicians and pharmacologists together in his program. One of the strongest arguments used against Leaf was the point that many clinicians ignore the core knowledge of chemistry, absorption, distribution, metabolism and excretion of drugs, dose response, etc., that are essential to any pharmacology, clinical or otherwise. In one form or another this statement was made by Maren, Papper, Freedman, Melmon, Whitsett, Oates, Cooper, and Hailman. Oates, Burns, and Melmon were particularly careful to identify the common denominator uniting clinical pharmacologists and requiring participation of a pharmacology department. Dose-response relations, comparative potency, interactions between drugs, drug disposition, the relation between the concentration of a drug in the plasma and its effect, genetic factors, etc., were all included.

Burns added that pharmacogenetics and immunopharmacology represent promising areas for basic pharmacologists to enter and unite more strongly with clinical pharmacology. Freedman, Winter, and Papper all expressed confidence that the clinical pharmacologist who feels ill at east in the basic 
pharmacology department need not remain that way if proper steps are taken. Richardson and Freedman warned against the lack of flexibility that might follow if clinical pharmacology were tied to one clinical group. Papper and Gurley emphasized the need for teaching in pharmacology to be strongly oriented toward clinical pharmacology (echoing an earlier statement of Oates that teaching must not be secondary to any other consideration in the mind of a clinical pharmacologist), but once the importance of clinical problems is accepted by a pharmacology department, clinical pharmacologists should be related to basic pharmacology "without compromise." Papper and Gurley felt that the interfaces between clinical pharmacology and the various clinical specialties will be best preserved by basing clinical pharmacology in a pharmacology department. The interface with pediatrics received special attention after Palmisano took clinical pharmacologists to task for neglecting this important area. However, Mirkin described a strong relation between clinical pharmacology and pediatrics at Minnesota, and Azarnoff's report indicated that 11 clinical pharmacology programs include participation of pediatrics departments. Other interfaces receiving particular attention during the Conference were those with anesthesiology (Elliott), industry (Nance), psychiatry (Burns and Freedman), and toxicology (Gurley). Melmon described an interesting program in which clinical pharmacology cooperates with a research group in pharmacy that provides expertise in pharmacokinetics, organic chemistry, mathematics, and drug assays in body tissues.

At the same time, Melmon urged clinical pharmacologists to abandon the "octopus concept" that would require them to be involved in a huge number of simultaneous activities, almost without limit. In this regard Martz felt that efficacy reviews of large numbers of drugs might waste huge amounts of clinical pharmacologists' time. Oates, Maren, and Elliott all agreed that a pharmacology department is certainly the best place in which to put a clinical pharmacology training program. Thirty-five of the 36 programs reviewed by Azarnoff have at least some relation to basic pharmacology departments. New compounds, which Burns termed the lifeblood of clinical pharmacology, are more likely to be studied by programs that have close relations to pharmacology departments, though it must be admitted that some pharmacology departments do not currently have a very impressive record in this regard. The important role of industry in providing such new compounds was emphasized by Hodges. Indeed, the excitement that comes from an important effect of a new compound in man is probably the strongest attraction of clinical pharmacology, an attraction that Sjoerdsma, Burns, and Hodges all listed as paramount. The admittedly rare success of this type makes all the other work (including much dull routine) worthwhile. In a final attack on Leaf's thesis, Hailman observed that clinical specialists of the type mentioned by Leaf are best qualified to do the type of study that the pharmaceutical industry least needs. In summary, Leaf served the Conference well. By avoiding the soap-boxery so often used by challengers, he set a tone of rational discussion rather than heated argument. But his proposals received extensive criticism.

But clinical pharmacology must be afflicted with other problems for, as Papper stated, this field is not flourishing as it should. Training programs that last only one year are too short to contribute much to the field, in the opinion of Maren, Oates, and Azarnoff. Oates mentioned the diffculty in reaching members of the house staff in medical centers; Whitsett explained that the attitude of many clinicians who considered diagnosis far more important than therapy is transmitted to the house staff. Gilman added that adverse ideas about the pharmaceutical industry and its products filter down from the United States Congress all the way to medical students. 
The pharmaceutical industry is ground between governmental regulations (a complaint of Martz, Gilman, Hailman, and Sjoerdsma) and the aloof attitude of many clinical pharmacologists (a complaint of Martz, Nance, and Hailman). Edwards and Finkel defended the Food and Drug Administration while Oates and Azarnoff defended clinical pharmacologists, respectively, against the two specifications of the above charge. As a representative of the pharmaceutical industry who also has a very long record of interest in clinical pharmacology training, Kohlstaedt was in the least controversial position during this argument.

Sjoerdsma gave one of the most emphatic talks of the Conference as he reviewed various dismal experiences with regulations. He seriously suggested emigration to Europe as a possible solution. This suggestion led Gross to warn against considering Europe as any Utopia for clinical studies. Although Rall noted that some types of study are more easily carried out in England than in the United States, Hodges predicted that this favorable (to England) difference might be more apparent than real and, in any event, transitory. In a comment from the audience, Dr. W. J. R. Taylor asked the Conference to consider ways to ease the heavy burden of Congressional pressure on the FDA and to provide some mechanism whereby the FDA can perform a positive function rather than merely a negative, regulatory function. As Oates and Sjoerdsma agreed, the FDA has had trouble with its own image and this has certainly been no help to clinical pharmacology in general.

The public (and its lawyers) accept the benefits associated with new drugs, but they are unwilling to accept the inevitable hazards associated with the use of effective drugs. In making the last comment, Martz did not confine his criticism to the FDA. $\mathrm{He}$ added that "budget time is a bad time for clinical pharmacology in most schools." As Oates and Papper reminded the Conference, clinical pharmacologists do not have the same source of clinical income as most other clinicians, and this problem adds to the financial woes of clinical pharmacology. Thus, manpower in the field remains short and recruiting continues to be difficult (Oates). Pelikan and Hodges added that recruitment for all pharmacology, not simply clinical pharmacology, should concern the Conference.

Azarnoff reported results of a survey taken under the auspices of the American Society for Pharmacology and Experimental Therapeutics, indicating that 101 out of 131 training positions in clinical pharmacology were filled at the time of the survey. A second survey suggests that medical schools now have about 120 full-time clinical pharmacologists, with approximately 100 more devoting a considerable part of their time to this activity, but Azarnoff gave reasons for considering this figure an over-estimate. By 1980, each medical school, according to its currently listed needs, will require for the staffing of its clinical pharmacology programs about five more individuals than it is likely to get, at the current rate of production of clinical pharmacologists. Clark's figures suggested a need for 500 clinical pharmacologists within the next few years, with perhaps 250 as a realizable goal by 1976 . Hodges felt that at least 200 would be needed, whereas Hailman predicted a much greater requirement than the above figures would suggest.

The most significant aspect of the various projections and estimates was their consensus that the output of clinical pharmacologists, at the current rate of production, will fall far below the need. Yet, as Freedman, Bass, and others repeated, the climate is not salubrious for clinical pharmacology or indeed for other types of advanced teaching and research at the present moment. The demand for health care is increasing, while the funding of much research and teaching is decreased. Moreover, there is strong pressure to train physicians more quickly and thus increase the number of practicing physicians. An 
increased number of physicians, faced with an increased number of individuals demanding health care, will probably react with an inordinate increase in the prescribing of drugs. In such an environment, the failure to provide for increased teaching of clinical pharmacology at all levels of medical education will be especially damaging. We may return to the situation described by Moliere, when, according to one of his characters, most people were dying of their remedies rather than their maladies.

Not all clinical pharmacology activities have happy endings, and Elliott candidly described discouraging experiences with a "pain clinic"; one might say it turned out to be more of a pain than a clinic. But Elliott stressed that such examples can hardly serve as an indictment of the whole field. If "the ability to use drugs wisely is a good test of a physician" (Lee), many schools are not preparing their students to pass this test.

Palmisano felt that clinical pharmacologists themselves had failed in their recruiting of pediatricians, for less than 15 per cent of pediatric departments have any individuals with a joint appointment in pediatrics and pharmacology. However, Mirkin, as noted above, described an important pediatric-clinical pharmacology relation at Minnesota. Many studies which might be considered pedestrian and calling for little talent on the part of the investigator when carried out in adults are important, difficult, and a major challenge to any investigator's ingenuity when the subjects are infants or children. Burns, Christensen, and Palmisano described several of the special problems of methodology, including number of available subjects, informed consent, and translation of data from animals to man. Pharmacokinetic studies are greatly needed in the pediatric age groups (Azarnoff).

The status of clinical pharmacology thus appeared reasonably healthy when studied with a low-power lens but much less encouraging when examined under higher magnification. Many suggestions for improvement were made during the course of the two days. Oates outlined an important mechanism in which superior teaching as well as research can establish a positive feedback, with greater knowledge of clinical pharmacology attracting greater numbers of trainees who may themselves subsequently become teachers. He mentioned conferences, rounds, rotating assignments of house staff to clinical pharmacology programs, etc., as possible mechanisms to improve instruction but warned against accepting the value of any specific teaching method in this area until the method has been evaluated. (If such evaluations have been carried out, they must be very well-kept secrets, it appears.)

Whitsett suggested that activities of clinical pharmacologists, including counseling of other investigators in experimental design, serving as reference sources for information about many drugs, and providing expertise in the study of adverse reactions, are still underdeveloped. He recalled the statement of the late Dr. John Colmore, a leader in early-phase studies of new compounds in man, that clinical pharmacologists should be first of all leaders in the evaluation of new drugs. Clark and Nance agreed strongly with Whitsett's presentation and discussed various possibilities of providing increased support for such studies of new drugs.

Whitsett called on clinical pharmacologists to improve their teaching of students, especially to improve their students' ability to interpret the extensive literature and advertisements concerned with drugs. Burns noted that clinical pharmacologists might well teach many other investigators some of the facts of life in this regard. Martz suggested that therapeutics should perhaps be restored to the medical curriculum as a subject in its own right. Although courses given in the last year of medical school give medical students their most easily identifiable exposure to clinical pharmacology (Oates), exposure during all four years of medical school would be desirable 
(Papper). Clinical pharmacologists are doing increasing amounts of teaching of basic pharmacology (Gurley) while increasing their participation in such areas as poison control, etc. Hodges and Papper joined Gurley in the conclusion that one must use skilled teachers of pharmacology wherever they may be found, whether in basic or clinical pharmacology groups. It was widely agreed that clinical pharmacology must continue to be concentrated in one administrative unit and that this unitregardless of specific arrangements in any given medical center-must have a base in pharmacology and important relations with clinical specialties such as internal medicine. Finkel and Cooper both held out hope that some of the regulatory problems associated with drug research may lessen in the near future. Although the Conference members warmly welcomed this hope and also credited its proponents with charity, many in the Conference appeared to lack faith in this matter. Legislation may actually grow more, rather than less, strict unless mechanisms for peer review of drug therapy are established (Freedman). A steady increase in restrictive legislation is already visible (Sjoerdsma).

Goldberg suggested that lack of funds has probably replaced lack of clear image as the biggest single problem facing clinical pharmacology. Clinical pharmacology need not plan an expansion into every medical school in the country overnight in order to make advances, but increased financial support is essential (Oates, Burns, Richardson). Clark and Freedman discussed the possibility of further support through a career investigator program; Oates reiterated the need for long-term salary support, a need that is now under study by the PMA (Winter). Zubrod suggested special awards to increase the number of pediatric clinical pharmacologists. Burns described current industrial support of certain clinical pharmacology units which are are not based in medical schools but do everything a medical school clinical pharmacology unit does, using the facilities of non-university hospitals. He believes that industrial support will be needed increasingly not only for clinical pharmacology but also for basic pharmacology. Hailman, however, felt that this entire area of support is a problem for government more than industry. Maren felt it essential that schools themselves increase their funding, while Papper focused the call for support onto clinical departments. The present level at which many trainees' stipends are fixed by law is a serious problem (Clark).

The spatial constraint under which many clinical pharmacology programs operated was so pressing in 1965 that it received italic emphasis in the report of the Basin Harbor Conference. Martz reminded the 1970 Conference that this need still exists in many medical centers, although solutions have been achieved in some. Maren supplies the space for clinical pharmacology in the pharmacology department. Elliott agreed that there are advantages in providing clinical pharmacology with its central space in a pharmacology department, provided the clinical pharmacologists have joint appointments with their appropriate clinical departments and are thus frequently present in the clinical areas. He pointed out that a clinical pharmacology division which has its main physical base in a department of internal medicine provides certain difficulties for other clinical disciplines that wish to participate in the clinical pharmacology program.

A succinct description of the type of individual that clinical pharmacology wishes to recruit was given by Zubrod, as he described the qualities that the Burroughs Wellcome Foundation sought in its candidates: scientific ability, clinical ability, leadership ("spark and imagination"), a real interest in the fate of drugs and normal compounds in man, ability to "carve out a place" in his own school, plus the motivation and ability to be a teacher. These criteria created a successful selection system, for the schools to which successful candidates have gone are clearly 
showing a continued interest in the teaching and practice of rational therapy of diseased people. Cooper described six different areas in which governmental programs require clinical pharmacologists and, in my opinion, gave one of the best answers ever made to the implied question: How can anyone be a clinical pharmacologist, since he cannot be an expert in the use of every drug? Cooper pointed out that a clinical pharmacologist can serve as a "resident expert" who admittedly is not the final expert for each drug but can nevertheless ask the right questions and stimulate the work that will provide their answers. Cooper did not feel that some form of certification of clinical pharmacologists should necessarily be dismissed as a poor idea. His presentation also reminded the Conference that the prophylactic trial is as much a part of clinical pharmacology as the therapeutic trial.

Cooper, Lee, Kohlstaedt, and Zubrod all gave examples of the need for more multicenter trials. Elliott and Palmisano suggested that professional societies have not been sufficiently involved in clinical pharmacology activities. The safety aspect which Edwards expressed as a major concern of the FDA might be better served if relatively simple, early studies received more attention, in defiance of present academic insistence on elegant studies as the only acceptable type. Hailman termed such simple, early studies "clinical sharpshooting"; Gilman and Gross agreed that simplicity should not automatically be considered a vice, with the crown of virtue reserved for complicated studies alone. A system of local peer review might replace some FDA regulations (Sjoerdsma), but local review is not likely to be any panacea for the stifling effects of regulations.

As Goldberg noted at the end, the shortage of clinical pharmacologists remains: both the "genetically pure" type described by Gilman and the specialty-oriented clinician who conducts good clinical investigations with drugs are needed in larger numbers. The major site of training must continue to be medical schools. To increase the number of clinical trials conducted in academic institutions, every medical school will probably need at least five additional clinical pharmacologists. Clinical pharmacologists, while maintaining their own units, must also work to reverse the trend of disappearing pharmacology departments in some medical schools. 